\title{
BMJ Open Beliefs, practices and knowledge of community pharmacists regarding complementary and alternative medicine: national cross-sectional study in Lebanon
}

\author{
Mohamad Ali Hijazi, ${ }^{1}$ Hibeh Shatila, ${ }^{2}$ Abdalla El-Lakany, ${ }^{1}$ Maha Aboul Ela, ${ }^{1}$ \\ Samer Kharroubi, ${ }^{2}$ Mohamad Alameddine, ${ }^{\circledR 3,4}$ Farah Naja ${ }^{2}$
}

To cite: Hijazi MA, Shatila $H$, El-Lakany A, et al. Beliefs, practices and knowledge of community pharmacists regarding complementary and alternative medicine: national cross-sectional study in Lebanon. BMJ Open 2019;9:e025074. doi:10.1136/ bmjopen-2018-025074

- Prepublication history and additional material for this paper are available online. To view these files, please visit the journal online (http://dx.doi org/10.1136/bmjopen-2018025074).

MA and FN contributed equally.

Received 29 June 2018 Revised 3 January 2019 Accepted 22 January 2019

Check for updates

(C) Author(s) (or their employer(s)) 2019. Re-use permitted under CC BY-NC. No commercial re-use. See rights and permissions. Published by BMJ.

For numbered affiliations see end of article.

Correspondence to Dr Mohamad Alameddine; ma164@aub.edu.lb and Professor Farah Naja; fn14@aub.edu.lb

\section{ABSTRACT}

Introduction Pharmacists are uniquely positioned to provide patients with evidence-based information in order to ensure effective and safe use of Complementary and alternative medicine (CAM) products.

Objective Assess beliefs, practices and knowledge related to CAM products among community pharmacists in Lebanon.

Design, methods and setting Using stratified random sampling, a nationally representative survey was conducted among community pharmacists in Lebanon. Through face-to-face interviews, pharmacists completed a multicomponent questionnaire consisting of four sections: (1) sociodemographic characteristics; (2) beliefs related to regulation of CAM products, role of media in promoting their safe use, availability of resources and continuing education; (3) practices including selling CAM products, providing advice for patients and reporting adverse effects and (4) knowledge about specific CAM products, their uses, side effects and interactions.

Results A total of 341 pharmacists agreed to participate (response rate: $86 \%$ ). Only pharmacists with complete data were included in this study $(n=310)$. Pharmacists agreed that CAM products are effective $(63.8 \%)$ and that they should be exclusively sold in pharmacies (80.3\%), but disagreed that commercially marketed CAM products are well regulated $(63.5 \%)$ and that media plays a positive role in educating users about these products (55.8\%). As for practices, $64.5 \%$ of pharmacists were always or often advising patients on safe use; however, $74.2 \%$ of participants rarely or never reported adverse effects. Regarding knowledge, although the majority of pharmacists were aware of the uses of CAM products, fewer knew about their side effects and their interactions with drugs. After adjustment for covariates, receiving education/training on CAM products during university was the sole predictor of higher knowledge score $(B=0.68$, $95 \% \mathrm{Cl} 0.29$ to 1.07 ).

Conclusions This study revealed positive beliefs of pharmacists in Lebanon towards CAM products and indicated important gaps in their practice and knowledge. Deliberate efforts to enhance the education of pharmacists are warranted to ensure the safe integration and use of CAM products in Lebanon.

\section{Strength and limitations of this study}

- This is the first study to survey a nationally representative sample of community pharmacists in Lebanon with an $86 \%$ response rate.

- The study employed a context-specific questionnaire examining beliefs, practices and knowledge of complementary and alternative medicine (CAM) products among community pharmacists.

- The data collection relied on self-reported answers which could be subject to errors due to memory recall or social desirability bias.

- The cross-sectional nature of the study prevented any inference about the change in beliefs, practice or knowledge related to CAM products over time among pharmacists in the country.

\section{INTRODUCTION}

Complementary and alternative medicine (CAM) is a diverse group of medical and healthcare systems, practices and products that are not considered part of conventional medicine. CAM may complement mainstream medicine by diversifying the conceptual frameworks of medicine or by satisfying a demand that has not been met by orthodoxy. ${ }^{1}$ The US National Center for Complementary and Integrative Health divides CAM into two main categories: (1) CAM products, such as herbs, vitamins and minerals and probiotics; and (2) mind and body therapies, including yoga, chiropractic and osteopathic manipulation, meditation and massage therapy. ${ }^{2}$ In recent years, there has been a worldwide renaissance of interest in these CAM products whereby their global market exceeded US $\$ 100$ billion during year 2017 . $^{3}$ Prevalence rate as high as $70 \%$ were reported for natural CAM products' use among the general population in various countries such as Canada 
and Kuwait. ${ }^{45}$ CAM products are usually used for general health maintenance, treatment of specific disease states and more frequently for chronic conditions (eg, anxiety, pain, headaches, depression and cancer). ${ }^{6}$ Such widespread use of CAM products could be attributed to dissatisfaction with conventional medicine, the increasing cost of conventional medical care, placebo effect and the desire to be involved in the decision-making process related to one's health. ${ }^{78}$ However, it is important to note that the use of CAM products might be associated with hazardous health risks related to their adverse effects, improper dosage or quality of the products (eg, contamination, misidentification or lack of standardisation).$^{9}$ These risks could be amplified due to the low rate of disclosure to healthcare providers for fear of their disapproval, disinterest or inability to help. ${ }^{10-13}$ Such lack of professional supervision may further expose the consumer to various risks, including adverse reactions or interactions with conventional drugs. ${ }^{61415}$

Among healthcare professionals, pharmacists are ideally positioned to promote the effective and safe use of CAM products by providing patients with evidence-based information. Professional associations, such as the American College of Clinical Pharmacy (ACCP), the American Society of Health-System Pharmacists and the Canadian Society of Hospital Pharmacists, have recommended that the profession of pharmacy actively embrace dietary supplements (natural health products, vitamins and minerals) as part of the pharmacist's scope of practice. ${ }^{16}$ The ACCP's stated that 'the pharmacist's involvement in herbal products is an extension of their roles in pharmaceutical care, clinical pharmacy practices and collaborative healthcare teams'. ${ }^{17}$ Despite this marked commitment to promoting the safe use of CAM products by pharmacists, the integration of CAM into the curricula of pharmacy education has lagged behind ${ }^{18}$ leaving many pharmacists unfamiliar with the health effects of CAM products. ${ }^{16}$

The Middle East and North Africa region hosts a growing market of CAM products. ${ }^{19-25}$ However, in many countries of the region, including Lebanon, this market remained poorly regulated and subject to abuse by both patient and provider. ${ }^{26}$ About one-third of Lebanese adults $(29.87 \%)$ were reported to use CAM in 2015, with the most prevalent being CAM products, specifically herbal supplements. ${ }^{7}$ Higher rates of use were reported among patients with chronic diseases such as infertility $(41 \%),{ }^{27}$ lung cancer $(41 \%),{ }^{28}$ and HIV and AIDS conditions $(46.6 \%) .{ }^{29}$ A common finding to most of the aforementioned studies was the low rate of disclosure to the treating physicians. ${ }^{72628}$ 30-32 This raised concerns about CAM safety, efficacy and impact on the patient health, especially when its use is coupled with poor regulatory frameworks. ${ }^{26}$

In Lebanon, the high prevalence of use of CAM products and their poorly regulated market, in addition to the high rate of non-disclosure to healthcare providers, underscore the crucial role of pharmacists in ensuring patients' health and safety. The Lebanese Ministry of
Public Health $(\mathrm{MoPH})$ regulates the profession of pharmacy, through granting two licensures: (1) the license to practice for pharmacists and (2) the license to open a pharmacy. For the latter, the pharmacist ought to be registered within the Order of Pharmacists in Lebanon (OPL) ${ }^{33}$

The primary objective of this study was to assess the beliefs, practices and knowledge related to CAM products among a nationally representative sample of community pharmacists in Lebanon. A secondary objective of the study was to investigate the sociodemographic determinants of knowledge related to CAM products among study participants. The findings of this study will inform the practice of pharmacy in the country, as well as the development and integration of CAM modules into mainstream educational programmes of pharmacy.

\section{METHODS}

This is a cross-sectional national survey of pharmacists practising in community pharmacies which was conducted in Lebanon between September 2017 and February 2018. The sampling unit for this study was the pharmacy. A list of all community pharmacies and their location was obtained from the OPL. Pharmacies were selected from this list using a stratified random sampling technique. The strata were the six Lebanese governorates. Within each stratum (governorate), pharmacies were selected at random from the list of all pharmacies within this stratum. The number of pharmacies selected was proportional to the total number of pharmacies in each stratum. Sample size calculations showed that a minimum of 342 pharmacists ought to be recruited in order to estimate a prevalence of $50 \%$ with a $95 \% \mathrm{CI}$ and a margin of error of $5 \%$. In order to account for a $14 \%$ refusal rate, 396 pharmacies were selected from the OPL list.

To be included in the study, the pharmacist had to be (1) licensed to practice by MoPH, (2) registered in the OPL, (3) working in the selected pharmacy either as pharmacy owner or as an employee and (4) conversant in either English or Arabic languages. Pharmacists who were unable or unwilling to give consent for the study were not included. If a pharmacist in a selected pharmacy refused to participate, the pharmacist in the closest pharmacy was approached. In the case when more than one pharmacist in the selected pharmacy was eligible to participate, only one pharmacist was selected at random.

Data collection took place in the selected pharmacies. Through face-to-face interviews with the pharmacists, a multicomponent questionnaire was completed. Each interview lasted $10-15 \mathrm{~min}$. The interviews were conducted by field workers who received extensive training on professional interviewing techniques and administration of the questionnaire prior to the start of the study. In order to increase the participation rate, the interviewers were trained to clearly explain the purpose of the study and the potential benefits of its results for 
the pharmacy profession and the health and well-being of the patients.

The design of the questionnaire used in the data collection for this study was informed by a thorough review of relevant literature ${ }^{16232434}$ and by a careful examination of the local context. The content validity of this questionnaire was confirmed by an expert panel consisting of a pharmacist, a nutrition epidemiologist, a biostatistician and a health policy expert. The questionnaire was originally written in English, before being translated to the Arabic language, and then back-translated to English. The original and back-translated English versions of the questionnaire were examined to ensure parallel form reliability. The questionnaire comprised four sections. The first section included questions related to sociodemographic, education and practice characteristics, such as age, sex, employment status (full-time employee, part-time employee or pharmacy owner), highest level of education attained (Bachelors, Masters, Pharm D or $\mathrm{PhD}$ ), whether the pharmacist received education/ training related to CAM during his/her university education years or post-graduation, years of experience as community pharmacist, the number of pharmacists in the pharmacy and how long was the pharmacy open for. The latter question was included because, in the local context, the longer the duration the pharmacy has been opened for, the more likely its clientele would develop a personalised relationship with the pharmacist allowing for better communication of their health needs and concerns. The second section of the questionnaire addressed the pharmacist's beliefs related to CAM products. Specific questions were included tackling his/her perception of the regulation of CAM products' market in Lebanon, the role of media in educating consumers about the safe use of these products as well as the availability of resources and the need for continuous education. Section 3 included questions assessing the pharmacist's practices in relation to CAM products, such as selling, advising a patient on safe use, reporting of adverse effects and checking for drug interactions. For sections 2 and 3, the survey instrument used a 5-point Likert rating scale in which 1 represented strongly agree and 5 represented strongly disagree. The last section of the questionnaire addressed the pharmacist's knowledge about CAM products. A total of 10 questions were selected to address the uses, side effects and drug interactions of commonly sold CAM products in the Lebanese market. According to a previous investigation by the authors, vitamin $\mathrm{C}$ was the most commonly sold CAM product (25\%), followed by ginseng (22\%), vitamin B (13\%), gingko (14\%), omega-3 fatty acids $(9.5 \%)$, echinacea $(9.5 \%)$ and valerian $(7.4 \%) .^{35}$ The formulation of the questions around these products was carried out by an expert panel of pharmacists including $\mathrm{MH}$, MA (authors) and Dr Ghassan Al Amine (previous president of the OPL), and in consultation with the relevant literature. ${ }^{23} 36$ The questionnaire was pilot tested on a convenient sample of 16 pharmacists to check for clarity and culture sensitivity. Data collected during the pilot testing phase of the questionnaire were not included in this study. A copy of the questionnaire used in data collection is provided as the online supplementary file to this manuscript.

For the summary of the data, descriptive statistics were used, such as frequencies and proportions. A knowledge score corresponding to the number of correctly answered questions was generated. Pharmacists were assigned a score value of ' 1 ' for any specific question that they have answered correctly and ' 0 ' if their answer was wrong. An 'I do not know' answer was also given a ' 0 ' because it reflected lack of knowledge. For each pharmacist, the assigned values for all questions were summed to obtain their respective knowledge score. Given that the questionnaire included 10 questions to evaluate knowledge, the score could range between a minimum of 0 and a maximum of 10 . The resulting score was considered as a continuous variable, with no specific cut-off, whereby higher values indicated better knowledge. Simple and multiple linear regression analyses were used to investigate the associations of sociodemographic factors with knowledge, using the knowledge score as dependent variable and the sociodemographic factors as independent variables. $P$ values $<0.05$ were considered statistically significant. Statistical Package for Social Sciences (SPSS) software V.20.0 for windows program was used to analyse the data.

\section{Patient and public involvement}

The specific aims of this study were to assess beliefs, practices and knowledge related to CAM products among community pharmacists in Lebanon. The specific target population of this study was community pharmacists. While there was no direct input of patients or members of the public into the design of this study, the outcomes could potentially benefit the public at large through enhancing the safe use of CAM products and their proper integration into the healthcare system. The results of this study will be disseminated through various means including published papers, presentations and executive summaries sent to concerned stakeholders.

\section{RESULTS}

Out of 396 pharmacists approached, 341 agreed to participate in this study ( $86.1 \%$ response rate). The two main reasons for refusal to participate were lack of interest $(34.5 \%)$ and lack of time $(27.3 \%)$. Of the 341 questionnaires, only those with complete data were included in this study $(\mathrm{n}=310)$.

The distributions of the pharmacies in Lebanon and the study sample are presented in table 1. Overall, compared with the national distribution, the study sample showed similar proportions of pharmacies among the various governorates. 
Table 1 Distribution of pharmacies across governorates in this study in comparison with national distribution of pharmacies

\begin{tabular}{lcc}
\hline & $\begin{array}{l}\text { Pharmacies in the } \\
\text { study, } \mathbf{n}(\%)\end{array}$ & $\begin{array}{l}\text { Pharmacies in } \\
\text { Lebanon, } \mathbf{n}(\%)\end{array}$ \\
\hline Beirut & $30(9.7)$ & $238(7.8)$ \\
South & $44(14.2)$ & $353(11.6)$ \\
North & $47(15.2)$ & $436(14.3)$ \\
Mount Lebanon & $122(39.4)$ & $1311(43.1)$ \\
Beqaa & $43(13.9)$ & $482(15.8)$ \\
Nabatieh & $24(7.7)$ & $223(7.3)$ \\
Total & 310 & 3043 \\
\hline
\end{tabular}

\section{Characteristics of the study sample}

Table 2 displayed the various characteristics of the study population. The pharmacists were of varied age groups, with most of them aged below 40 years $(67.1 \%)$. The study sample consisted of a slightly higher proportion of males versus females $(53.5 \%$ males and $46.5 \%$ females). More than half of the pharmacists approached were the owners of the pharmacy $(54.8 \%)$, while the remaining were either working as full-time $(23.2 \%)$ or part-time (21.9\%). As for the educational level, $54.5 \%$ reported were having a Bachelor's degree, while $45.5 \%$ of the pharmacist had attained higher degrees: $18.4 \%$ a Master's degree, $24.2 \%$ a Pharm D and $2.9 \%$ a PhD. Sixty-five per cent of the pharmacists studied in Lebanese universities. More than two in three pharmacists $(73.2 \%)$ reported receiving education about CAM products during their university education, and only $17.7 \%$ underwent a post-graduation training on CAM products. Working experience among the pharmacists ranged from 1 to 3 years $(22.9 \%)$ to $>10$ years $(43.9 \%)$ (table 2$)$.

CAM, complementary and alternative medicine.

\section{Beliefs related to CAM products, their market and availability} of resources

Overall, study participants displayed positive general beliefs related to CAM products with $63.8 \%$ and $80.3 \%$ of pharmacists strongly agreeing or agreeing that CAM products are effective and that CAM products should be exclusively sold in pharmacies, respectively (table 3 ). Only $30.0 \%$ disagreed or strongly disagreed that CAM products have fewer side effects compared with conventional medicines $(17.4 \%$ were neutral and $52.5 \%$ strongly agreed or agreed). Over $80.0 \%$ strongly agreed or agreed that providing information to customers about CAM products is a pharmacist's professional responsibility (table 3).

CAM, complementary and alternative medicine.

As for the pharmacists' beliefs related to the CAM products' market in the country, a sizeable proportion of survey participants $(41.9 \%)$ disagreed or strongly disagreed that CAM products in the Lebanese market are well standardised and of good quality. When asked if they think that the market for CAM products in Lebanon is well regulated, $63.5 \%$ of surveyed community pharmacists
Table 2 Characteristics of study sample $(n=310)$

\begin{tabular}{|c|c|c|}
\hline & Frequency & Percentage \\
\hline \multicolumn{3}{|l|}{ Age range, years } \\
\hline 20-30 & 112 & 36.1 \\
\hline $31-40$ & 96 & 31.0 \\
\hline $41-50$ & 55 & 17.7 \\
\hline$>50$ & 47 & 15.2 \\
\hline \multicolumn{3}{|l|}{ Gender } \\
\hline Male & 166 & 53.5 \\
\hline Female & 144 & 46.5 \\
\hline \multicolumn{3}{|l|}{ Employments status } \\
\hline Full-time & 72 & 23.2 \\
\hline Part-time & 68 & 21.9 \\
\hline Pharmacy owner & 170 & 54.8 \\
\hline \multicolumn{3}{|c|}{ Highest educational level attained } \\
\hline Bachelors & 169 & 54.5 \\
\hline Masters & 57 & 18.4 \\
\hline Pharm D & 75 & 24.2 \\
\hline $\mathrm{PhD}$ & 9 & 2.9 \\
\hline \multicolumn{3}{|c|}{ Which university did you graduate from } \\
\hline $\begin{array}{l}\text { Non-Lebanese } \\
\text { Universities }\end{array}$ & 86 & 27.7 \\
\hline Lebanese Universities & 203 & 65.5 \\
\hline Did not specify & 21 & 6.8 \\
\hline
\end{tabular}

During your university education, did you receive any education/training on CAM products?

$\begin{array}{lrc}\text { Yes } & 227 & 73.2 \\ \text { No } & 83 & 26.8 \\ \text { Did you receive any } & \text { postgraduate education/training on } \\ \text { CAM products? } & & \\ \text { Yes } & 55 & 17.7 \\ \text { No } & 255 & 82.3\end{array}$

Years of work experience (in community pharmacy)

$\begin{array}{lrl}1-3 & 71 & 22.9 \\ 4-7 & 68 & 21.9 \\ 8-10 & 35 & 11.3 \\ >10 & 136 & 43.9\end{array}$

How many pharmacists work in this pharmacy, in addition to yourself?

$\begin{array}{lrr}0 & 20 & 6.5 \\ 1 & 121 & 39.0 \\ 2 & 113 & 36.5 \\ \geq 3 & 56 & 18.1\end{array}$

How long has this pharmacy been opened for?

\begin{tabular}{lll}
$1-5$ years & 77 & 24.8 \\
$6-10$ years & 70 & 22.6 \\
$11-15$ years & 37 & 11.9 \\
$16-20$ years & 38 & 12.3 \\
\hline
\end{tabular}

Continued 
Table 2 Continued

\begin{tabular}{lcc}
\hline & Frequency & Percentage \\
\hline >20years & 63 & 20.3 \\
Do not know & 25 & 8.1 \\
\hline
\end{tabular}

disagreed or strongly disagreed. Furthermore, more than half of pharmacists $(55.8 \%)$ disagreed or strongly disagreed that media plays a positive role in educating patients about CAM products (table 3 ).

With regards to the availability of resources on the safe use of CAM products for pharmacists, only $55.5 \%$ of study participants believed that information on CAM products are easily accessible to the pharmacists and $61.9 \%$ strongly agreed or agreed that continuous education in this field should be mandatory for pharmacists (table 3).

\section{Current practices of dispensing CAM products}

More than two-thirds of pharmacists $(68.7 \%)$ participating in this study reported that they always/often sell CAM products in their pharmacy and $59.4 \%$ reported always/often getting inquiries from patients regarding the use of CAM products (table 4A). The majority of pharmacists $(64.5 \%)$ reported that they always/often advise patients on safe use of CAM products and ask for their feedback after use; however, $74.2 \%$ of pharmacists answered that they rarely or never reported adverse effects that occurred with patients using CAM products (table 4A). Among those who reported the incidence of adverse effects, $53.4 \%$ of pharmacists indicated that they reported it to the pharmaceutical company (provider of CAM) and only $15.5 \%$ reported to the OPL, whereas the remaining reported to physician $(13.8 \%)$, medical representative $(8.6 \%)$ and $\mathrm{MoPH}(5.2 \%)$. A couple of pharmacists reported the adverse effects to other pharmacists working with them in the same pharmacy (table 4B). It is worth noting that $60.3 \%$ of pharmacists reported frequently checking for CAM product-drug interaction prior to selling the product (table $4 \mathrm{~A}$ ).

\section{Evaluation of pharmacists' knowledge}

Table 5 displayed the results of knowledge which included 10 questions addressing uses, side effects and drug interactions of commonly sold CAM products in Lebanon. The majority of pharmacists answered correctly the questions related to the uses of Echinacea, Ginkgo biloba and omega-3 (81.9\%, 83.2\% and $93.5 \%$ respectively). However, only $24.5 \%$ recognised the effect of echinacea on autoimmune disorders, $61.3 \%$ were aware that ginkgo might increase the risk of bleeding when combined with warfarin, 21.9\% knew that ginseng does not affect blood pressure and $50.3 \%$ did not know the potential effect of a vitamin B complex supplement on wound healing. On the other hand, $78.4 \%$ of the pharmacist knew that vitamin $\mathrm{C}$ enhances the absorption of iron. Of further concern were the high proportions of interviewed pharmacists who were not aware of the interactions between drugs and CAM products. For instance, $80.7 \%$ did not know that valerian should be used cautiously in patients using benzodiazepines and $80.9 \%$ did not answer correctly the

Table 3 General beliefs towards CAM products, their market and availability of resources among a national sample of community pharmacists in Lebanon $(n=310)$

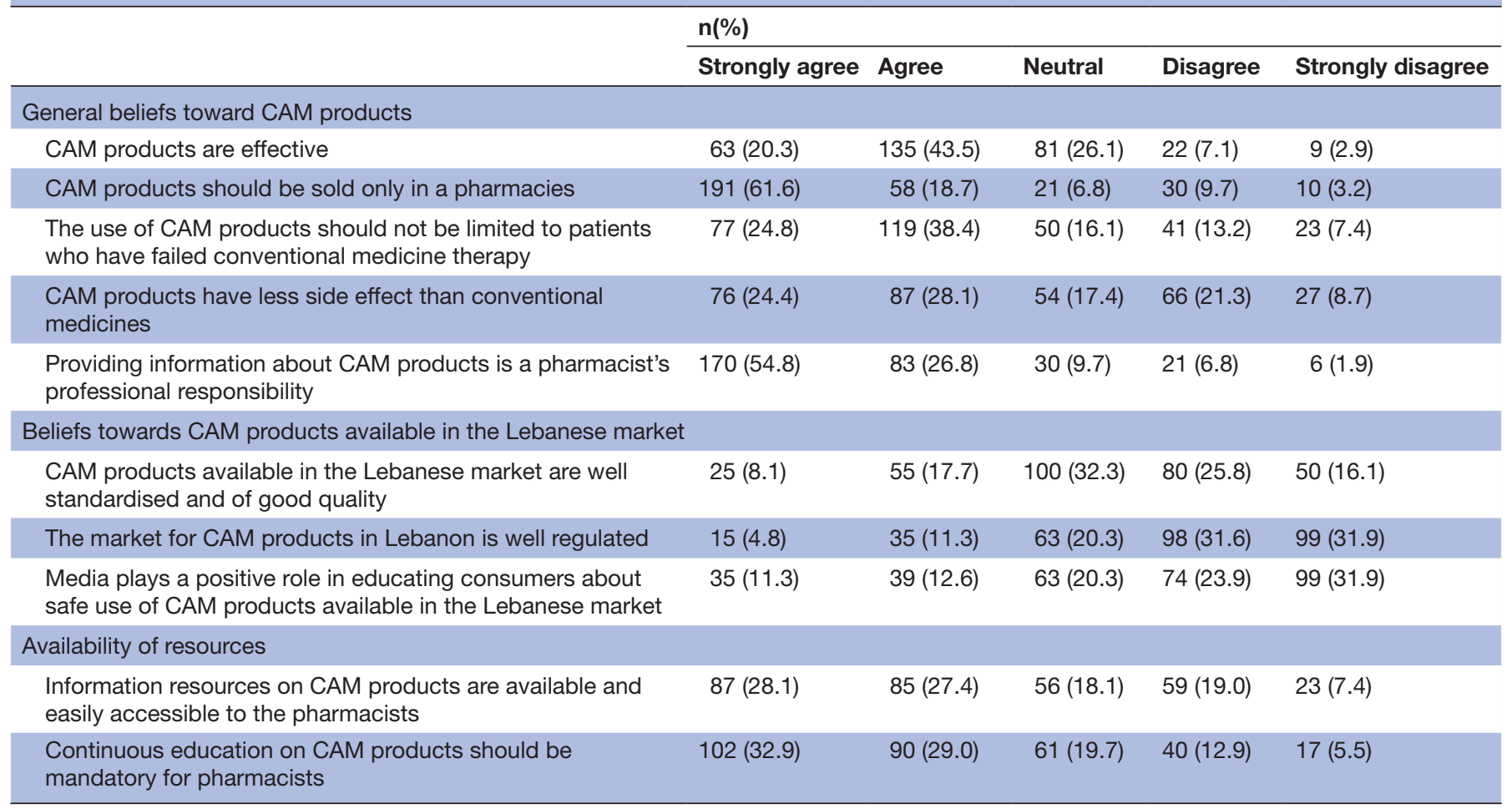


Table 4A Current practices of dispensing CAM products among a national sample of community pharmacists in Lebanon $(n=310)$

\begin{tabular}{|c|c|c|c|c|c|}
\hline & Always & Often & Sometimes & Rarely & No \\
\hline $\begin{array}{l}\text { Do you get inquiries from patients regarding the use of CAM } \\
\text { products? }\end{array}$ & $92(29.7)$ & $92(29.7)$ & $69(22.3)$ & $38(12.3)$ & $19(6.1)$ \\
\hline Do you advise patients on safe use of CAM products? & $126(40.6)$ & $74(23.9)$ & $72(23.2)$ & $22(7.1)$ & $16(5.2)$ \\
\hline $\begin{array}{l}\text { Do you ask your patient about their feedback after their use of CAM } \\
\text { products? }\end{array}$ & $136(43.9)$ & $57(18.4)$ & $56(18.1)$ & $43(13.9)$ & $18(5.8)$ \\
\hline Do you get referrals from naturopath to your pharmacy? & $21(6.8)$ & $38(12.3)$ & $52(16.8)$ & $42(13.5)$ & $157(50.6)$ \\
\hline Do you check for CAM product-drug interaction? & $121(39.0)$ & $66(21.3)$ & $44(14.2)$ & 38 (12.3) & $41(13.2)$ \\
\hline
\end{tabular}

CAM, complementary and alternative medicine.

concurrence administration of omega-3 and clopidogrel (table 5).

\section{Sociodemographic determinants of knowledge}

Overall, the score for knowledge ranged between 1 and 9 in the study population, with a mean of $5.32 \pm 1.43$. Simple linear regression results indicated that among all sociodemographic characteristics considered in this study, 'receiving education/training on CAM products during university' was the sole predictor of better knowledge ( $\beta=0.68,95 \%$ CI 0.31 to 1.06$)$. After adjustment for covariates, receiving education/training on CAM products during university was also positively correlated with higher knowledge score $(\beta=0.68,95 \%$ CI 0.29 to 1.07$)$, that is, receiving any education/training on CAM products increases the mean knowledge score by 0.68 while adjusting for sociodemographic characteristics (table 6).

\section{DISCUSSION}

This is the first national study to examine the beliefs, practices and knowledge related to CAM products among a nationally representative sample of community pharmacists in Lebanon. Additionally, it presents one of a few regional attempts to solicit the opinion of pharmacists at a national scale. The study revealed that the majority of

Table 4B To whom do you report any adverse effect that occurred with patients using CAM products?

\begin{tabular}{lcr}
\hline & $\mathbf{n = 5 8}$ & \% \\
\hline Pharmaceutical company & 31 & 53.4 \\
Medical representative & 5 & 8.6 \\
MoPH & 3 & 5.2 \\
OPL & 9 & 15.5 \\
Pharmacists & 2 & 3.4 \\
Physician & 8 & 13.8
\end{tabular}

CAM, complementary and alternative medicine; $\mathrm{MoPH}$, Ministry of Public Health; OPL, Order of Pharmacists in Lebanon. community pharmacists acknowledged the importance of CAM products, believed that the market should be better regulated and reported needing professional development opportunities to enhance their knowledge of CAM products. With regards to practices, pharmacists were found to frequently advise patients on safe use of CAM products; however, most did not report adverse effects. Furthermore, the assessment of knowledge unearthed some deficiencies in pharmacists' knowledge related to the potential side effects of CAM products and their potential interactions with drugs. Receiving education/ training on CAM products during university was the sole predictor of better knowledge among pharmacists.

One of the main findings of this study was related to the generally positive beliefs of Lebanese community pharmacists towards CAM products which is similar to other studies in the region ${ }^{19-24}$ and other countries such as USA, ${ }^{18}$ Australia, ${ }^{37}$ Singapore $^{38}$ and Ethiopia. ${ }^{3}$ The results of this study showed that pharmacists believed in the utility of CAM products and were willing to assume a leading role by asking for exclusive rights to sell these products in pharmacies and under the advice of community pharmacists. This is in accordance with a recent study by Asmelashe Gelayee $e t a l^{3}$ where pharmacists believed that they are ideally positioned to dispense CAM products, as part of their role in dispensing, monitoring and counselling conventional medicine. This unique position of the pharmacist could be best achieved if equipped with good knowledge and skills. ${ }^{3}$

The general positive beliefs of pharmacists towards CAM products were contrasted by doubts with regards to the quality of available CAM products and the regulations through which the market of these products is governed. Similarly, in other studies, pharmacists' main concerns were the lack of clear regulations and safety governing the sale of CAM products. ${ }^{18} 3839$ On that front, surveyed pharmacists were both critical of the regulatory framework for CAM products and the counterproductive and misleading role played by media. Concerning the regulation of media, Lebanon could perhaps learn from the 


\begin{tabular}{|c|c|c|c|}
\hline $\begin{array}{l}\text { True/ } \\
\text { False }\end{array}$ & $\begin{array}{l}\% \text { Answered } \\
\text { correctly }\end{array}$ & $\begin{array}{l}\% \text { Answered } \\
\text { incorrect }\end{array}$ & $\begin{array}{l}\% \text { Answered I } \\
\text { do not know }\end{array}$ \\
\hline $\mathrm{F}$ & $76(24.5)$ & $120(38.7)$ & $114(36.8)$ \\
\hline $\mathrm{F}$ & 68 (21.9) & $218(70.3)$ & $24(7.7)$ \\
\hline $\mathrm{T}$ & $190(61.3)$ & 42 (13.5) & 78 (25.2) \\
\hline $\mathrm{T}$ & $258(83.2)$ & $26(8.4)$ & $26(8.4)$ \\
\hline $\mathrm{T}$ & $290(93.5)$ & 9 (2.9) & $11(3.5)$ \\
\hline $\mathrm{F}$ & 59 (19.0) & $188(60.6)$ & $63(20.3)$ \\
\hline $\mathrm{F}$ & $154(49.7)$ & 41 (13.2) & 115 (37.1) \\
\hline
\end{tabular}

experience of the US Food and Drug Administration (FDA) which prohibits manufacturers and distributors of CAM products from marketing adulterated or misbranded products. ${ }^{40}$ From a regulatory point of view, there is no counterpart for the FDA in Lebanon. The MoPH has had some initiatives to protect consumers' health, but more efforts are needed to ensure public safety. ${ }^{26}$

A remarkable finding in this study related to over $50 \%$ of surveyed pharmacists reporting adverse effects of CAM products to the distributing companies rather than doing so to the MoPH. Such a practice does not only jeopardise public safety but also raises ethical questions related to the obvious conflict of interest in reporting adverse effects to the company benefiting from the sales of CAM products. Similar findings were reported in Qatar. ${ }^{39}$ These findings call for the establishment of a more robust regulatory framework that reaches beyond the review and approval of CAM products to the establishment and implementation of the mechanisms to monitor and evaluate the safe use post-market distribution. Such a role could be played by the MoPH, the OPL or an arm's length organisation with a national mandate to ensure safe consumption of CAM products. For instance, in the USA, the FDA is responsible for the regulation of dietary supplements. ${ }^{40}$ Manufacturers of CAM products are responsible for the evaluation of the safety and labelling of their products to meet the requirements of FDA regulations. FDA is responsible for taking action against any adulterated CAM products that have reached the market. ${ }^{40}$ In addition, the FDA allows consumers and healthcare professionals to report any adverse reactions on a designated reporting portal. ${ }^{41}$ Within this context, it is important to note that out of 123 pharmacists who had experience with reporting adverse effects, only 58 indicated to whom they report such effects $(47.2 \%)$. It is possible that participants were hesitant to answer this question because they were not sure about the correct answer. This further highlights the need to regulate the reporting of adverse effects and to clearly inform the pharmacists of the existing reporting channels.
In this study, the findings related to beliefs and practices of community pharmacists further underscored the need for pharmacists to play a leading role in ensuring the safe utilisation of CAM products by their customers. However, such a role of the community pharmacist may be undermined by the lack of proper education and training on the safe use of CAM products. In fact, in this study, close to two-thirds of pharmacists believed that continuous education on safe and efficient use of CAM products should be mandatory for pharmacists. This recommendation echoed that of many other studies highlighting the need to have additional education and training on the use of CAM products. ${ }^{3} 16$ 21-24 37-39

Perhaps one of the most disconcerting findings of this study was related to the deficiencies in the pharmacists' knowledge of potential interactions among CAM products and drugs and to a lesser extent CAM products' side effects. This lack of knowledge came along with prevalent good intentions of community pharmacists to provide the best evidence-based advice to their customers. These findings may lead to the advice of pharmacists being suboptimal and could, in some instances, jeopardise the health and well-being of the patients. The knowledge deficiencies found in this study were also reported by many studies in the region such as Saudi Arabia, ${ }^{623} \mathrm{Abu}$ Dhabi, ${ }^{24}$ Jordan, ${ }^{19}$ Kuwait, ${ }^{20}{ }^{21}$ Oman, ${ }^{22}$ Qatar,${ }^{39}$ Palestine ${ }^{42}{ }^{43}$ and $\mathrm{Iran}^{44}$ as well as other countries such as Ethiopia, ${ }^{3} \mathrm{USA}^{18}{ }^{18}$ Singapore, ${ }^{38}$ and in Trinidad and Tobago, ${ }^{45}$ and therefore appear to be a global concern. One possible explanation for the observed knowledge deficiencies could be the biased information propagated by some CAM product companies. This information usually aims to maximise sales and neglects any factor that can affect the promotion of their products. ${ }^{46} \mathrm{~A}$ few studies showed that personal sale visits of certain products' companies to pharmacists (called 'detailing') could drive prescriptions in favour of the product being promoted. This is true even though pharmacists' may be aware of the potential conflict of interest these visits precipitate. ${ }^{47-49}$ Another explanation 
Table 6 Simple and multiple linear regression analyses for the association of characteristics of study participants with the knowledge score

\begin{tabular}{|c|c|c|}
\hline & Crude $\mathrm{B}, 95 \% \mathrm{Cl}$ & Adjusted B, $95 \% \mathrm{Cl}$ \\
\hline \multicolumn{3}{|l|}{ Age range, years } \\
\hline $20-30$ & Ref & Ref \\
\hline $31-40$ & $-0.04(-0.45$ to 0.37$)$ & $-0.29(-0.86$ to 0.29$)$ \\
\hline $41-50$ & $-0.19(-0.68$ to 0.30$)$ & $-0.53(-1.27$ to 0.21$)$ \\
\hline$>50$ & $-0.51(-1.03,0.00)$ & $-0.74(-1.57$ to 0.10$)$ \\
\hline \multicolumn{3}{|l|}{ Gender } \\
\hline Male & Ref & Ref \\
\hline Female & $-0.05(-0.39$ to 0.29$)$ & $-0.19(-0.55$ to 0.17$)$ \\
\hline \multicolumn{3}{|l|}{ Employments status } \\
\hline Pharmacy owner & Ref & Ref \\
\hline Full-time & $0.38(-0.04$ to 0.79$)$ & $0.32(-0.15$ to 0.78$)$ \\
\hline Part-time & $-0.04(-0.47$ to 0.38$)$ & $-0.08(-0.60$ to 0.45$)$ \\
\hline \multicolumn{3}{|c|}{ Highest educational level attained } \\
\hline $\mathrm{BSc}, \mathrm{MSc}$ and $\mathrm{PhD}$ & Ref & Ref \\
\hline Pharm D & $0.37(-0.02$ to 0.76$)$ & $0.27(-0.14$ to 0.68$)$ \\
\hline \multicolumn{3}{|c|}{ Which university did you graduate from } \\
\hline $\begin{array}{l}\text { Non-Lebanese } \\
\text { Universities* }^{*}\end{array}$ & Ref & Ref \\
\hline Lebanese Universities & $0.05(-0.35$ to 0.26$)$ & $-0.06(-0.40$ to 0.28$)$ \\
\hline \multicolumn{3}{|c|}{$\begin{array}{l}\text { During your university education, did you receive any education/training } \\
\text { on CAM products? }\end{array}$} \\
\hline No & Ref & Ref \\
\hline Yes & 0.68 (0.31 to 1.06$)$ & 0.68 (0.29 to 1.07$)$ \\
\hline
\end{tabular}

Did you receive any post graduate education/training on CAM products?

\begin{tabular}{|c|c|c|}
\hline No & Ref & Ref \\
\hline Yes & $0.25(-0.19$ to 0.69$)$ & $0.25(-0.20$ to 0.70$)$ \\
\hline \multicolumn{3}{|c|}{ Years of work experience (in community pharmacy) } \\
\hline $1-3$ & Ref & Ref \\
\hline $4-7$ & $-0.28(-0.78$ to 0.22$)$ & $-0.22(-0.75$ to 0.30$)$ \\
\hline $8-10$ & $0.37(-0.24$ to 0.98$)$ & $0.67(-0.08$ to 1.42$)$ \\
\hline$>10$ & $-0.18(-0.62$ to 0.25$)$ & $0.15(-0.60$ to 0.87$)$ \\
\hline \multicolumn{3}{|c|}{ How many pharmacists work in this pharmacy? } \\
\hline 0 & Ref & Ref \\
\hline 1 & $-0.19(-0.91$ to 0.53$)$ & $-0.28(-1.01$ to 0.45$)$ \\
\hline 2 & $-0.28(-1.01$ to 0.44$)$ & $-0.56(-1.33$ to 0.21$)$ \\
\hline$\geq 3$ & $-0.05(-0.83$ to 0.73$)$ & $-0.31(-1.16$ to 0.54$)$ \\
\hline \multicolumn{3}{|c|}{ How long has this pharmacy been opened for? } \\
\hline $1-5$ years & Ref & Ref \\
\hline $6-10$ years & $0.13(-0.36$ to 0.63$)$ & $0.11(-0.40$ to 0.62$)$ \\
\hline $11-15$ years & $0.22(-0.38$ to 0.82$)$ & $0.24(-0.39$ to 0.88$)$ \\
\hline 16-20years & $0.19(-0.40$ to 0.79$)$ & $0.33(-0.32$ to 0.98$)$ \\
\hline$>20$ years & $-0.56(-0.45$ to 0.56$)$ & $0.35(-0.25$ to 0.94$)$ \\
\hline I do not know & $-0.39(-1.08$ to 0.30$)$ & $-0.38(-1.10$ to 0.34$)$ \\
\hline
\end{tabular}

*Including 'non-specified universities'.

CAM, complementary and alternative medicine.

could be the lack of availability and easy access of pharmacists to scientific resources and professional development programmes.
The findings on the lack of knowledge on safe use of CAM products, coupled with the majority of pharmacists requesting a mandatory continuous education programme, open a remarkable window of opportunity for the MoPH to work collaboratively with the OPL to establish a national programme for the continuous education of pharmacists on CAM products. Collaborating with academic institutions would enhance the design, implementation and evaluation of such a programme. Providing continuous education opportunities would enhance the knowledge of pharmacists on the safe use of CAM products, the appropriate reporting of side effects and their general role as counsellors for their customers. Last but not least, the finding in our regression models that receiving education/training on CAM products during university was the sole predictor of better knowledge calls on the pharmacy schools to revise their curricula in order to ensure proper education and training of pharmacy students on the safe use of CAM products. Such revision is necessary to enhance public safety.

The findings of this study ought to be considered in light of a few limitations. First, the data collection relied on self-reported answers for practices, beliefs and knowledge. These answers could be subject to errors due to memory recall or social desirability bias. To mitigate this, interviewers were trained to maintain a neutral attitude and avoid leading questions. Second, although a few questionnaires were validated to assess the beliefs, practices and knowledge related to CAM products among specific populations, such as nurses and medical students, ${ }^{50} 51$ none was available for use among pharmacists. Therefore, the questionnaire used in data collection was developed and vetted by a panel of experts, including a pharmacist, nutrition epidemiologist, biostatistician and a health policy expert. The questionnaire was designed to capture the common traits in beliefs, practices and knowledge of pharmacist towards CAM products and to address to context specificity of the study. It is important to note that a couple of the questions in the questionnaire were double-barrelled and could have been better broken into two questions each to ensure clarity and accuracy of the answer. Future studies are encouraged to examine the validity and reliability of questionnaires assessing beliefs, practices and knowledge of CAM products among pharmacists. Third, despite the fact that the sample of pharmacists considered was nationally representative, the cross-sectional nature of the study prevented any inference about the change in beliefs, practices or knowledge over time among pharmacists in the country. Lastly, this study relied mainly on quantitative assessment. Future studies aiming to qualitatively examine pharmacists' beliefs, practices and knowledge with regards to CAM products could complement the results of quantitative investigations and provide a complete evaluation of the subject matter.

In conclusion, the findings of this study revealed positive beliefs of pharmacists in Lebanon towards CAM products and indicated important gaps in their practice and 
knowledge. Given the central role that the pharmacists play in promoting the safe and efficient use of CAM products and in light of the study's findings, deliberate efforts to enhance the education of pharmacists and support them with a clear and responsive regulatory framework would be necessary to ensure the safe integration and use of CAM products in the country.

\section{Author affiliations}

${ }^{1}$ Department of Pharmaceutical Sciences, Beirut Arab University, Beirut, Lebanon ${ }^{2}$ Department of Nutrition and Food Sciences, American University of Beirut, Beirut, Lebanon

${ }^{3}$ Faculty of Health Sciences, American University of Beirut, Beirut, Lebanon ${ }^{4}$ Strategy \& Institutional Excellence, Mohammed Bin Rashid University of Medicine and Health Sciences College of Medicine, Dubai, Dubai, United Arab Emirates

Acknowledgements The authors would like to acknowledge the contribution of Samer Jallad and express their gratitude to the senior pharmacy students at Beirut Arab University (promotion 2018/2019) for their contribution to data collection. They would also like to thank the pharmacists who participated in this study.

Contributors FN and MAH: designed the data collection form and the methodology. MAH: managed data collection. SK and HS: analysed the data. FN, MAH, MA and HS: wrote the first draft of the manuscript. AE and MAE: contributed to drafting the paper. All authors reviewed and approved the final version.

Funding The authors have not declared a specific grant for this research from any funding agency in the public, commercial or not-for-profit sectors.

Competing interests None declared.

Patient consent for publication Not required.

Ethics approval This study protocol was approved by the Institutional Review Board (IRB) at the Beirut Arab University under the protocol number 2018H-0052-P-R-0249.

Provenance and peer review Not commissioned; externally peer reviewed.

Data sharing statement $A$ de-identified dataset related to this study could be made available with the approval of the IRB committee if necessary.

Open access This is an open access article distributed in accordance with the Creative Commons Attribution Non Commercial (CC BY-NC 4.0) license, which permits others to distribute, remix, adapt, build upon this work non-commercially, and license their derivative works on different terms, provided the original work is properly cited, appropriate credit is given, any changes made indicated, and the use is non-commercial. See: http://creativecommons.org/licenses/by-nc/4.0/.

\section{REFERENCES}

1. Ernst FR, Grizzle AJ. Drug-related morbidity and mortality: updating the cost-of-illness model. J Am Pharm Assoc 2001;41:192-9.

2. NIH. National center for complementary and integrative health $(\mathrm{NIH})$. https://nccih.nih.gov/ (Accessed 24th Aug 2018).

3. Asmelashe Gelayee D, Binega Mekonnen G, Asrade Atnafe S, et al. Herbal Medicines: Personal Use, Knowledge, Attitude, Dispensing Practice, and the Barriers among Community Pharmacists in Gondar, Northwest Ethiopia. Evid Based Complement Alternat Med 2017; $2017: 1-6$

4. Natural Health Products Directorate-Health Canada. Natural health product tracking survey-2010 final report. http://epe.lac-bac.gc.ca/ 100/200/301/pwgsc-tpsgc/por-ef/health/2011/135-09/report.pdf (Accessed 1st Sep 2018).

5. Awad A, Al-Shaye D. Public awareness, patterns of use and attitudes toward natural health products in Kuwait: a cross-sectional survey. BMC Complement Altern Med 2014;14:105.

6. Al-Arifi MN. Availability and needs of herbal medicinal information resources at community pharmacy, Riyadh region, Saudi Arabia. Saudi Pharm J 2013;21:351-60.

7. Naja F, Alameddine M, Itani L, et al. The use of complementary and alternative medicine among lebanese adults: results from a national survey. Evid Based Complement Alternat Med 2015;2015:1-9.

8. Iyer P, McFarland R, La Caze A. Expectations and responsibilities regarding the sale of complementary medicines in pharmacies: perspectives of consumers and pharmacy support staff. Int $J$ Pharm Pract 2017:25:292-300.

9. Azaizeh H, Saad B, Khalil K, et al. The state of the art of traditional arab herbal medicine in the eastern region of the mediterranean: a review. Evid Based Complement Alternat Med 2006;3:229-35.

10. Kwai Ping L. Role of complementary medicine in nursing and health care professionals. SOJ Nur health care. Role of Complementary Medicine in Nursing and Health Care Professionals 2015:1-2.

11. Kelak JA, Cheah WL, Safii R. Patient's decision to disclose the use of traditional and complementary medicine to medical doctor: a descriptive phenomenology study. Evid Based Complement Alternat Med 2018;2018:1-11.

12. Hunter D, Oates R, Gawthrop J, et al. Complementary and alternative medicine use and disclosure amongst Australian radiotherapy patients. Support Care Cancer 2014;22:1571-8.

13. Shim JM, Schneider J, Curlin FA. Patterns of user disclosure of complementary and alternative medicine (CAM) use. Med Care 2014;52:704-8

14. Lindly O, Thorburn S, Zuckerman K. Use and nondisclosure of complementary health approaches among US Children with developmental disabilities. J Dev Behav Pediatr 2018;39:217-27.

15. Agyei-Baffour P, Kudolo A, Quansah DY, et al. Integrating herbal medicine into mainstream healthcare in Ghana: clients' acceptability, perceptions and disclosure of use. BMC Complement Altern Med 2017; $17: 513$.

16. Kwan D, Hirschkorn K, Boon H. U.S. and Canadian pharmacists' attitudes, knowledge, and professional practice behaviors toward dietary supplements: a systematic review. BMC Complement Altern Med 2006;6:31.

17. Miller LG, Hume A, Harris IM, et al. White paper on herbal products. Pharmacotherapy 2000;20:877-91.

18. Harris IM, Kingston RL, Rodriguez $R$, et al. Attitudes towards complementary and alternative medicine among pharmacy faculty and students. Am J Pharm Educ 2006;70:129.

19. Khader Y, Sawair FA, Ayoub A, et al. Knowledge and attitudes of lay public, pharmacists, and physicians toward the use of herbal products in North Jordan. $J$ Altern Complement Med 2008:14:1186-7.

20. Awad Al, Al-Ajmi S, Waheedi MA. Knowledge, perceptions and attitudes toward complementary and alternative therapies among Kuwaiti medical and pharmacy students. Med Princ Pract 2012;21:350-4.

21. Abahussain NA, Abahussain EA, Al-Oumi FM. Pharmacists' attitudes and awareness towards the use and safety of herbs in Kuwait. Pharm Pract 2007;5:125-9.

22. Duraz AY, Khan SA. Knowledge, attitudes and awareness of community pharmacists towards the use of herbal medicines in muscat region. Oman Med J 2011;26:451-3.

23. Alkharfy K. Community pharmacists' knowledge, attitudes and practices towards herbal remedies in Riyadh, Saudi Arabia/ Connaissances, attitudes et pratiques des pharmaciens communautaires vis-a-vis des medicaments a base de plantes a Riyad (Arabie saoudite). Eastern Mediterranean Health Journal 2010;16:988.

24. Fahmy SA, Abdu S, Abuelkhair M. Pharmacists' attitude, perceptions and knowledge towards the use of herbal products in Abu Dhabi, United Arab Emirates. Pharm Pract 2010;8:109.

25. Gruenwald J, Herzberg F. The global nutraceuticals market. Business Briefing: Innovative Food Ingredients 2002:28-31.

26. Alameddine M, Naja F, Abdel-Salam S, et al. Stakeholders' perspectives on the regulation and integration of complementary and alternative medicine products in Lebanon: a qualitative study. BMC Complement Altern Med 2011;11:71.

27. Ghazeeri GS, Awwad JT, Alameddine M, et al. Prevalence and determinants of complementary and alternative medicine use among infertile patients in Lebanon: a cross sectional study. BMC Complement Altern Med 2012;12:129.

28. Naja F, Anouti B, Shatila $\mathrm{H}$, et al. Prevalence and correlates of complementary and alternative medicine use among patients with lung cancer: a cross-sectional study in Beirut, Lebanon. Evid Based Complement Alternat Med 2017;2017:1-11.

29. Abou-Rizk J, Alameddine M, Naja F. Prevalence and characteristics of CAM use among people living with hiv and aids in lebanon: implications for patient care. Evid Based Complement Alternat Med 2016:2016:1-11.

30. Naja F, Alameddine M, Abboud M, et al. Complementary and alternative medicine use among pediatric patients with leukemia: the case of Lebanon. Integr Cancer Ther 2011;10:38-46.

31. Naja F, Fadel RA, Alameddine M, et al. Complementary and alternative medicine use and its association with quality of life among 
Lebanese breast cancer patients: a cross-sectional study. BMC Complement Altern Med 2015;15:444.

32. Naja F, Mousa D, Alameddine M, et al. Prevalence and correlates of complementary and alternative medicine use among diabetic patients in Beirut, Lebanon: a cross-sectional study. BMC Complement Altern Med 2014;14:185.

33. Syndicate Of Pharmacists. Order of pharmacy lebanon. Beirut, Lebanon: Syndicate Of Pharmacists.

34. Song M, Ung CO, Lee VW, et al. Community pharmacists' perceptions about pharmaceutical service of over-the-counter traditional Chinese medicine: a survey study in Harbin of China. BMC Complement Altern Med 2017;17:9.

35. Hijazi M A-EM, Ellakany A. Overview of CAM Products in Lebanon: Results from Community Pharamcists survey.unpublished data.

36. Chang ZG, Kennedy DT, Holdford DA, et al. Pharmacists' knowledge and attitudes toward herbal medicine. Ann Pharmacother 2000;34:710-5.

37. Naidu S, Wilkinson JM, Simpson MD. Attitudes of Australian pharmacists toward complementary and alternative medicines. Ann Pharmacother 2005;39:1456-61.

38. Koh HL, Teo HH, Ng HL. Pharmacists' patterns of use, knowledge, and attitudes toward complementary and alternative medicine. $J$ Altern Complement Med 2003;9:51-63.

39. Kheir N, Gad HY, Abu-Yousef SE. Pharmacists' knowledge and attitudes about natural health products: a mixed-methods study. Drug Healthc Patient Saf 2014;6:7.

40. Administration FUSFaD. Dietary supplements. 2018 https://www.fda. gov/Food/DietarySupplements/ (Accessed 7th June 2018).

41. Administation FUSFaD. Safety reporting Portal. https://www. safetyreporting.hhs.gov/SRP2/en/Home.aspx?sid=24fc405f-58d24162-bb1a-f187b3be85df (Accessed 7th June 2018).

42. Shraim NY, Shawahna R, Sorady MA, et al. Community pharmacists' knowledge, practices and beliefs about complementary and alternative medicine in Palestine: a cross-sectional study. BMC Complement Altern Med 2017;17:429.

43. Khdour MR, Kurdi M, Hallak HO, et al. Pharmacists' knowledge, attitudes and practices towards herbal remedies. West Bank, Palestine: International Archives of Medicine, 2016.

44. Bastani P, Jooybar M, Zadeh M, et al. Community pharmacy-based survey on pharmacists' knowledge, attitude, and performance regarding dietary supplements: evidence from South of Iran. Natl J Physiol Pharm Pharmacol 2017;7:1-402.

45. Bahall M, Legall G. Knowledge, attitudes, and practices among health care providers regarding complementary and alternative medicine in Trinidad and Tobago. BMC Complement Altern Med 2017;17:144.

46. Ekor M. The growing use of herbal medicines: issues relating to adverse reactions and challenges in monitoring safety. Front Pharmacol 2014;4:177.

47. Kamal S, Holmberg C, Russell J, et al. Perceptions and attitudes of Egyptian health professionals and policy-makers towards pharmaceutical sales representatives and other promotional activities. PLoS One 2015;10:e0140457.

48. Hajjar R, Bassatne A, Cheaito MA, et al. Characterizing the interaction between physicians, pharmacists and pharmaceutical representatives in a middle-income country: a qualitative study. PLoS One 2017;12:e0184662.

49. Manchanda P, Honka E. The effects and role of direct-to-physician marketing in the pharmaceutical industry: an integrative review. Yale $J$ Health Pol'y L \& Ethics 2005;5:785.

50. Lie D, Boker J. Development and validation of the CAM Health Belief Questionnaire $(\mathrm{CHBQ})$ and $\mathrm{CAM}$ use and attitudes amongst medical students. BMC Med Educ 2004;4:2.

51. Belletti G, Shorofi SA, Arbon P, et al. Complementary and alternative medicine: italian validation of a questionnaire on nurses' personal and professional use, knowledge, and attitudes. J Nurs Meas 2017:25:292-304.

52. Karsch-Völk M, Barrett B, Kiefer D, et al. Echinacea for preventing and treating the common cold. Cochrane Database Syst Rev 2014;2:CD000530.

53. Lee AN, Werth VP. Activation of autoimmunity following use of immunostimulatory herbal supplements. Arch Dermatol 2004;140:723-7.

54. Hur M-H, Lee MS, Yang HJ, et al. Ginseng for reducing the blood pressure in patients with hypertension: a systematic review and meta-analysis. J Ginseng Res 2010;34:342-7.

55. Kelber O, Nieber K, Kraft K. Valerian: no evidence for clinically relevant interactions. Evid Based Complement Alternat Med 2014;2014:1-8

56. Ge B, Zhang Z, Zuo Z. Updates on the clinical evidenced herbwarfarin interactions. Evid Based Complement Alternat Med 2014:2014:1-18.

57. Stoddard GJ, Archer M, Shane-McWhorter L, et al. Ginkgo and warfarin interaction in a large veterans administration population: AMIA Annual Symposium Proceedings, 2015.

58. Weinmann S, Roll S, Schwarzbach C, et al. Effects of Ginkgo biloba in dementia: systematic review and meta-analysis. BMC Geriatr 2010;10:14

59. Rangel-Huerta OD, Gil A. Omega 3 fatty acids in cardiovascular disease risk factors: an updated systematic review of randomised clinical trials. Clin Nutr 2018;37:72-7.

60. Imantaeva GM, Mussagalieva AT. Omega-3 polyunsaturated fatty acids in treatment of patients with coronary heart disease and type 2 diabetes mellitus. International Journal of BioMedicine 2012(1):31-

61. Watson PD, Joy PS, Nkonde C, et al. Comparison of bleeding complications with omega-3 fatty acids + aspirin + clopidogrelversus-aspirin + clopidogrel in patients with cardiovascular disease. Am J Cardiol 2009;104:1052-4.

62. Opr M. Medicines Safety Update No. 2. 2010.

63. Neiva RF, Al-Shammari K, Nociti FH, et al. Effects of vitamin-B complex supplementation on periodontal wound healing. $J$ Periodontol 2005;76:1084-91.

64. Posthauer ME, Dorner B, Collins N. Nutrition: a critical component of wound healing. Adv Skin Wound Care 2010;23:560-72.

65. Lane DJ, Richardson DR. The active role of vitamin C in mammalian iron metabolism: much more than just enhanced iron absorption! Free Radic Biol Med 2014;75:69-83. 